\title{
The revolution of pulmonary arterial hypertension
}

\author{
Sergio Harari \\ Affiliation: U.O. di Pneumologia e Terapia Semi-Intensiva Respiratoria - Servizio di Fisiopatologia Respiratoria \\ ed Emodinamica Polmonare, Ospedale San Giuseppe - MultiMedica IRCCS, Milan, Italy.
}

Correspondence: Sergio Harari, U.O. di Pneumologia e Terapia Semi-Intensiva Respiratoria - Servizio di Fisiopatologia Respiratoria ed Emodinamica Polmonare, Ospedale San Giuseppe - MultiMedica IRCCS, Via San Vittore 12, Milan 20123, Italy. E-mail: sharariahotmail.it

0 @ERSpublications

If there has been a revolution in medical therapy in recent decades, it is the treatment of PAH http://ow.ly/1RWN305ibQ3

Once a death sentence, pulmonary arterial hypertension (PAH) came to be treated by heart-lung transplantation [1] followed by double lung transplant after the discovery of the right ventricle's extraordinary capacity for recovery and remodelling (figure 1) [2]. These advances subsequently led to the introduction of continuous intravenous prostacyclin therapy and a radical change in the prognosis of $\mathrm{PAH}$ [3], which was followed by oral therapies alone or in combination.

All this took place in an extraordinary flurry of research that led to the identification of the main pathways underlying the pathogenesis of endothelial dysfunction and the vascular remodelling responsible for PAH.

Over the years we have come to realise how PAH can develop following exposure to the HIV virus or to different drugs, namely appetite suppressants, or within the framework of comorbidities like connective tissue disease. Genetics has also played a cardinal role thanks to the discovery of key mutations predisposing to PAH as a heritable disease [4], in addition to potential pathogenetic pathways for targeted treatments.

All this and much more has been discovered, such as the role of physical exercise and rehabilitation. Previously deemed harmful and dangerous, exercise was subsequently reappraised in terms of the patient's functional recovery and stabilisation and has markedly improved the quality of life of PAH patients. The progressive shift in clinical guidelines from a strictly anatomo-pathological classification to a therapy-based approach has been a major step forward in improving PAH diagnosis, follow-up and treatment strategies [4].

Patient organisations, initially set up as national associations and then grouped into a European association, are also playing a key role in directing research towards new objectives. In the wake of much improved survival rates, the paper by GraARup et al. [5] published in this issue of European Respiratory Review discusses the needs, engagement and self-management of PAH patients. This issue contains eight articles on PAH from the 15th International Pulmonary Hypertension Forum held in Barcelona in March 2016. The articles document the transition from single therapies targeting just one pathogenetic pathway to the concept of combination therapy [6], and discuss the use of treatments targeting the prostacyclin pathway [7]. Other highly interesting aspects are tackled in articles from leading experts in the field. RAINA and HUMBERT [8] discuss the importance of risk factors in PAH development, while SimONNEAU et al. [9] offer an extraordinary overview of future research prospects, outlining the potential targets for new therapeutic approaches to PAH including mitochondrial dysfunction, iron deficiency, pulmonary artery denervation and others. Two further papers address special conditions such as the management of adult patients after the Fontan procedure [10] and the

Received: Oct 122016 | Accepted: Oct 132016

Conflict of interest: Disclosures can be found alongside this article at err.ersjournals.com

Provenance: Submitted article, peer reviewed.

Copyright OERS 2016. ERR articles are open access and distributed under the terms of the Creative Commons Attribution Non-Commercial Licence 4.0. 

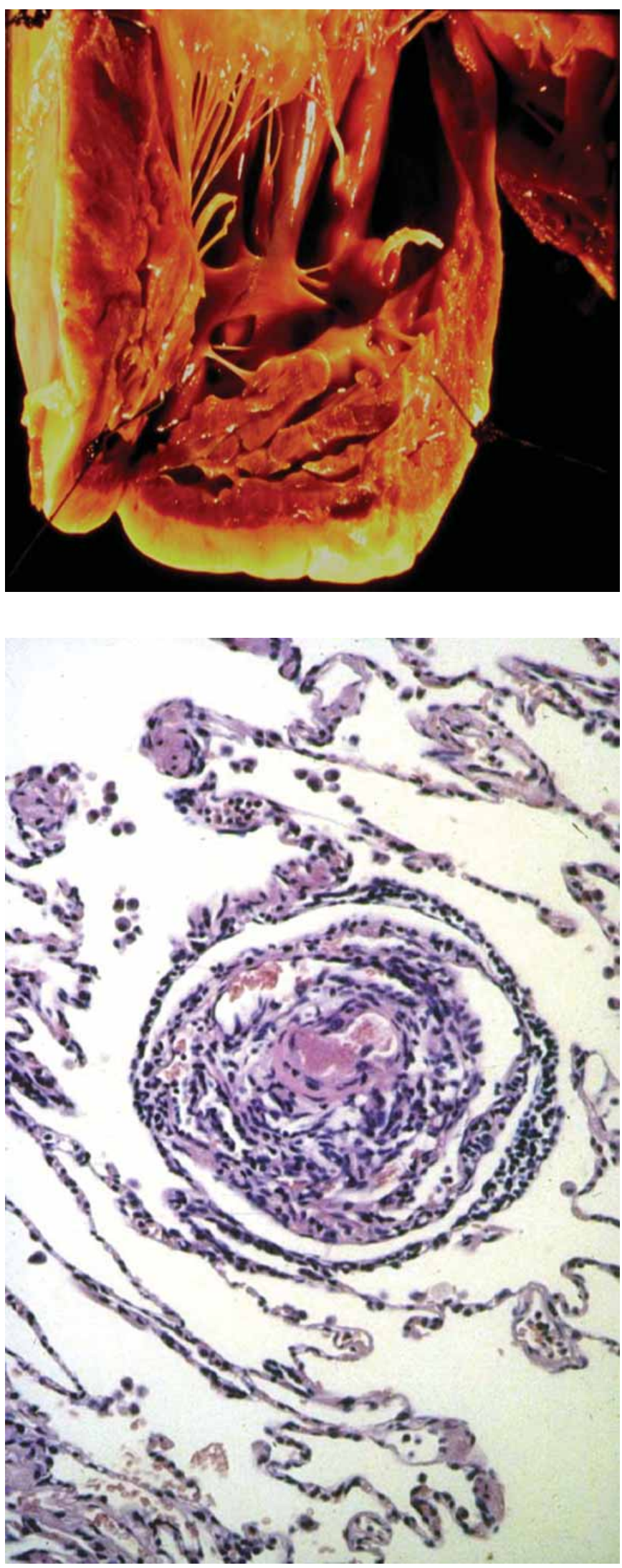

FIGURE 1 Severe right heart hypertrophy in a post mortem specimen of a patient with pulmonary arterial hypertension.
FIGURE 2 A typical onion ring histological plexiform lesion, a hallmark of pulmonary hypertension.

risks and difficulties of managing PAH in pregnant women [11]. This series of cutting-edge papers begins with an article by MEHTA and VACHIÉRY [12] emphasising the importance of making the right diagnosis of pulmonary hypertension, and discussing illustrative cases of great educational value (figure 2). 
Together, these contributions offer an excellent up-to-date focus on pulmonary hypertension topics observed from a variety of view-points from world-renowned experts in the field. The next issue of the European Respiratory Review will publish another outstanding series of articles on chronic post-embolic pulmonary hypertension, thereby completing this overview of hot topics and the latest scientific advances in this constantly evolving field of medicine.

\section{References}

1 Reitz BA, Wallwork JL, Hunt SA, et al. Heart-lung transplantation. Successful therapy for patients with pulmonary vascular disease. N Engl J Med 1982; 306: 557-564.

2 Christie JD, Edwards LB, Kucheryavaya AY, et al. The registry of the International Society for Heart and Lung Transplantation: the 29th adult lung and heart-lung transplant report. J Heart Lung Transplant 2012; 31: 1073-1086.

3 Rubin LJ, Mendoza J, Hood M, et al. Treatment of primary pulmonary hypertension with continuous intravenous prostacyclin (epoprostenol). Results of a randomized trial. Ann Intern Med 1990; 112: 485-449.

4 Galiè N, Humbert M, Vachiery JL, et al. 2015 ESC/ERS Guidelines for the Diagnosis and Treatment of Pulmonary Hypertension. Eur Respir J 2015; 46: 1855-1856.

5 Graarup J, Ferrari P, Howard L. Patient engagement and self-management in pulmonary arterial hypertension. Eur Respir Rev 2016; 25: 399-407.

6 Sitbon O, Gaine S. Beyond a single pathway: combination therapy in pulmonary arterial hypertension. Eur Respir Rev 2016; 25: 408-417.

7 Farber HW, Gin-Sing W. Practical considerations for therapies targeting the prostacyclin pathway. Eur Respir Rev 2016; 25: 418-430.

8 Raina A, Humbert M. Risk assessment in pulmonary arterial hypertension. Eur Respir Rev 2016; 25: 390-398.

9 Simonneau G, Hoeper MM, McLaughlin V, et al. Future perspectives in pulmonary arterial hypertension. Eur Respir Rev 2016; 25: 381-389.

10 Clift P, Celermajer D. Managing adult Fontan patients: where do we stand? Eur Respir Rev 2016; 25: 438-450.

11 Olsson K, Channick R. Pregnancy in pulmonary arterial hypertension. Eur Respir Rev 2016; 25: 431-437.

12 Mehta S, Vachiéry J-L. Pulmonary hypertension: the importance of correctly diagnosing the cause. Eur Respir Rev 2016; 25 : $372-380$. 